\title{
Lessons Learned in Designing and Implementing a Mission Focused Study Abroad Course
}

\author{
Diane Wise ${ }^{1}$, Jenny B. Schuessler ${ }^{1}$, Lourdes Cody $^{1} \&$ Deborah Davison ${ }^{1}$ \\ ${ }^{1}$ School of Nursing, Tanner Health System, University of West Georgia, Carrollton, USA \\ Correspondence: Diane Wise, MSN, RN, CNM CNE, Assistant Professor, School of Nursing, Tanner Health \\ System, University of West Georgia, 1601 Maple Street, Carrollton, GA 30118, USA.
}

Received: April 27, 2017

Accepted: May 20, 2017

Online Published: May 31, 2017

doi:10.20849/ijsn.v2i1.156

URL: https://doi.org/10.20849/ijsn.v2i1.156

\begin{abstract}
Introduction: Based on Duffy's (2009) Quality Caring Model and Hill and Watson's Caring Science Curriculum Model (2011), the School of Nursing embraces the philosophy that caring collaborative relationships are the center of a culture of quality caring in nursing. Culture and cultural competence are integral to caring. Immersion experiences have been identified as impacting cultural competence (Bentley \& Ellison, 2007; Kohlbry, 2016; Larsen \& Reif, 2011; Long, 2012). Methodology: This paper describes the planning, implementation and lessons learned from an immersion experience as part of a mission focused study abroad course to Quito, Ecuador. Discussion: Twelve students, three faculty, and two nurse practitioners cared for approximately 100 patients per day for 10 days. Lessons learned related to faculty, students and logistics are discussed. Results: Students demonstrated positive outcomes related to critical thinking and clinical reasoning, holistic care of diverse populations, communication and collaboration, professional accountability, and effective teaching strategies.
\end{abstract}

Keywords: study abroad, immersion experience, medical missions

For more than a decade, the faculty of a University School of Nursing (SON) in the southeastern United States has embraced the belief that caring collaborative relationships are the center of creating a culture of quality caring in nursing education and practice (Wilson \& Grams, 2013). The philosophy of the SON integrates Duffy's (2009) Quality Caring Model and Hill and Watson's (2011) Caring Science Curriculum Model to provide a framework for implementation of a curriculum based on caring. The commitment to a caring philosophy should be more than an academic exercise. According to Hill and Watson, nurse educators must "nurture this culture of caring if students are to graduate as competent caring nurses" (p.129) with the skills, knowledge and attitudes needed to provide quality health care.

Integral to caring are the concepts of culture and cultural competence. Culture is the specific pattern of behavior that characterizes a society and gives meaning to manifestations of care (Leininger \& McFarland, 2006). Cultural competence is an ongoing process that promotes the skills, knowledge and attitudes necessary for providing quality care for diverse populations (California Endowment, 2003). Poor outcomes and health disparities have been related to lack of cultural competence (Betancourt, Corbert, \& Bondaryk, 2014; Institute of Medicine [IOM], 2002, March), leading to a call by the American Association of Colleges of Nursing (AACN, 2008) to prepare culturally competent nurses. Various strategies can be used to teach cultural competence, but immersion experiences have been identified as having a significant impact (Bentley \& Ellison, 2007; Kohlbry, 2016; Larsen \& Reif, 2011; Long, 2012,).

In response to the call for cultural competence in nursing education and in congruence with a caring philosophy, the faculty assessed curricular practices to determine various approaches to promote both caring and cultural competency skills in students. A need for change in the focus of the study abroad program was identified. The previous study abroad program focused on observation to learn about the health care system of a European country. Faculty determined that a study abroad that focused on health care delivery to an underserved population in an immersion experience would have more impact in terms of applying caring and cultural competency skills. This article describes the planning, implementation and lessons learned of a hands - on mission focused study abroad course based in Quito, Ecuador. 


\section{Preliminary Steps}

A due diligence trip and partnering with an experienced agency are key elements to planning a successful Study Abroad in a third world country. In this case, Servants in Faith and Technology (SIFAT) was the expert resource. As a leader in providing opportunities for medical mission trips for over 30 years, their expertise provided assistance with safe lodging and transportation, meals, site location, and clinical experience. A due diligence trip was done by faculty with SIFAT five months prior to the trip. It was ascertained that the experience would readily meet the course objectives. Additionally, the university's Office of Education Abroad (OEA) was also invaluable in exploring the possibility of this trip. Through their collaborative guidance, the study abroad experience remained consistent with overall university core values. The OEA was also instrumental in the areas of logistics, initial student applications, and budget preparation.

The due diligence trip provided evidence that students would need physical assessment skills, the ability to triage, knowledge of medications, proficiency in team leadership, and an understanding of growth and development in order to successfully participate. Therefore, faculty decided that this experience would be open to students who had completed a minimum of two clinical courses, the holistic health assessment course, and the two pathophysiology/ pharmacology courses. With these pre-requisites determined, students were offered options in terms of course credit. This three credit hour course could be taken as an elective or in place of a senior level clinical course.

The student learning objectives of this study abroad experience included:

Table 1. Course outcome objectives

\begin{tabular}{ll}
\hline 1. & $\begin{array}{l}\text { Apply critical thinking and critical reasoning skills in providing competent, safe, person-centered } \\
\text { care in a specialty clinical environment. }\end{array}$ \\
\hline 2. & Provide holistic care to persons while demonstrating respect for diverse cultures. \\
\hline 3. & Communicate clearly and effectively in oral, electronic and written communication. \\
\hline 4. & $\begin{array}{l}\text { Collaborate effectively with persons and inter-professional health care teams in the planning, } \\
\text { management, prioritization, and evaluation of client care. }\end{array}$ \\
\hline 5. & $\begin{array}{l}\text { Implement effective teaching strategies to empower clients and their families to achieve positive } \\
\text { health care goals. }\end{array}$ \\
\hline 6. & Demonstrate accountability for personal and professional behavior in all clinical settings. \\
\hline
\end{tabular}

\section{The Work before the Work}

With the preliminary work complete, the tasks became those of building the faculty and health care provider team and raising funds to support the trip. Recruitment and preparation of students was critical. Perhaps the most challenging tasks were coordinating the purchase and packing of more than 300 pounds of medication and supplies. These preparations took weeks and untold hours of work.

\subsection{Building the Faculty and Health Care Provider Team}

Quito, Ecuador is known for its altitude, which can cause unpredictable health concerns for those unused to it. Additionally, both physical and emotional demands upon the faculty would be higher than usual due to extended and long clinical hours, the need for faculty to have expertise in a multitude of roles, an increase in their accountability to meet course objectives, assumption of continuous responsibility over the students, and ability to garner and retain authority. It was vital that the faculty selection criteria was done with those abilities as priorities. (Hegedus, et. al., 2013). Other selection criteria may include the faculty person's past civic involvement, a desire to help those in need, and most of all a desire to want to work with students outside the classroom. (Audette, et. al., 2013, p. 66)

Guided by the Director of OEA and the SIFAT representatives, it was determined that twelve students and five faculty would be needed to staff the clinics. Three of the faculty were easily identified as they were the core team from the beginning, and one of them was a midwife. The challenge was to identify and recruit two other health care providers. The dean identified several potential providers and sent each one an email about the purpose of the trip and invited participation. The response was immediate and two nurse practitioners from the University Student 
Health Services clinic who were willing to split the time of the trip as well as a former faculty member who was currently practicing as a nurse practitioner were chosen to serve as the providers along with the faculty midwife.

\subsection{Raising Funds: Student Scholarships, Faculty Support, Supplies and Medications}

Many of the undergraduate students at our university receive financial aid through Pell Grants or federally funded student loans. The administrative stipend charged to students which provided financial support to the faculty attending the trip was a student expense in addition to tuition. It was therefore critical to provide as much scholarship support as possible to the students. The dean and development officer identified SON supporters known to have an interest in supporting medical missions. Through an email, letters, and personal contact, the dean and development officer reached out to this group of people. This process achieved a significant amount of student scholarship support. An example of the generosity shown was the action that one of the donors took to sponsor all students who had never traveled outside of the United States. The OEA also contributed an amount of support to each student for the trip. However, all students did have some out of pocket expenses that they covered through loans or personal funds.

Another major aspect of the "work before the work" was the identification of the supplies and medications that would be needed, and finding funding to purchase these items. SIFAT's expertise provided guidance about what medications and supplies were specifically needed. The academic practice partnership with a local medical center opened the door for a significant amount of donated medications. SIFAT also knew of a company that sold medications for purposes such as this trip. With the help and commitment of a local physician, the certificate that authenticates the purpose and destination that was needed to guarantee that the supplies would get through customs was procured. Other, non-pharmaceutical, supplies were obtained through donations from medical supply companies that have a close working relationships with the SON, with members of the team, and with other faculty. During these times of uncertainty and learning, contact with SIFAT was almost constant. The benefits of partnering with the experts were undeniable.

\subsection{Recruiting and Preparing Students}

One final, critical step was that of selecting and preparing the student team. The faculty that attended the due diligence trip visited every class that consisted of students who met minimum course criteria. A focused presentation that included impactful pictures about the culture, clinical experiences and clients that would be served was shown. The presentation included a realistic but engaging overview of the team at work. Students were able to get a visual of the work that they would be doing and this made recruitment easy.

The OEA was responsible for all the paper work. Their office had all the required forms on a software program. This software made it effortless for the faculty to track passports, physical forms, payments, and all the necessary documents. The faculty was able to log in at any time and see the status of every student. According to Hegedus (2013), the maturity and reliability of student participants is key since it is impossible to supervise students every moment while away. Screening of applicants is highly recommended in the areas of GPA, a written essay which focuses on their personal motivation for participation, any history of previous international experiences, and an interview with faculty. (Hegedus, et. al, 2013; Memmott et. al., 2010). Due to a late start in planning, these recommendations were not taken which did result in a few undesired consequences that will be addressed in a later section of this paper.

Preparing the students included making sure they understood the mental, physical and emotional stressors inherent in this experience. The students were multicultural and multiethnic and it was important to inform them about the faith-based aspects of the program.

\subsection{Understanding Life as a Third World Citizen}

SIFAT provides an experience at their home base in Alabama that simulates a third world, and it was decided that this would be of benefit to our "first world" students. Their participation over the two-and-one-half day experience became the first activity towards their final course grade. Provided with only the most basic of needs such as a sleeping bag, medications, and bug spray, students spent these days learning how to make their own fire, cook over a huge pot, and live without cell phones! Team building exercises were instrumental in developing camaraderie among the students, a group that consisted of students from two different cohorts who did not know each other well.

The students also learned about Ecuador, the culture, the most common medical conditions, and the trip itinerary to expect. They were able to discuss the challenges people of underdeveloped nations must face daily, such as maintaining a fire all day to cook meals, the time consuming job of preparing and cooking a meal, how the smoke from the cook fires damages eyes and lungs, and the challenges to maintain hygienic conditions. They even had to 
purify the river water before drinking. This experience provided a great introduction to the mental, emotional and physical challenges to be faced in a study abroad, and the bonding among team members proved to be critical to the success of this study abroad medical mission trip.

\section{The Work}

Arriving in Quito, Ecuador, on a Saturday after an overnight flight from Atlanta, the weekend was spent as tourists; visiting the equator, learning the town of Quito, and of course shopping. On Monday the work in Puengasi began. The clinic was based in a church, and the women of the church were both experienced and dedicated to their tasks of signing the patients in, preparing and serving the team's lunch, and ministering to patients. The patients were people of the local community as well as a few who were displaced after an earthquake that occurred on the coast the previous week. The most common patient needs were musculoskeletal discomforts in the elderly due to their difficult lifestyles, vaginitis, and skin irritations. Many young mothers and their infants were also seen. Prior to leaving, each patient was given an oral treatment against parasites, a common finding in this population. The patients spoke either Spanish or Quichua (Keech-wa), the native language of the indigenous people, which made the need for interpreters vital. The clinic was busy, congested, noisy, and friendly.

The second week, the clinic was in Atacucho and was set up in the Community Center and led by the director of the preschool/day care program. The community leaders and day care workers were influential in the organization of this clinic. While the space was larger, the team had to construct exam rooms out of tarp and tape. A community physician joined our team for a few days and saw some of her regular patients. While these patients seemed to have more regular healthcare, they appeared needier and more desperate. The team cared for more chronically ill patients at this site and treated more lice, fungal, and scabies infestations. Many of the daycare children were treated for mild upper respiratory congestion and infections. Because the children spent many hours in very close proximity to each other, when one child had something infectious, they would all get it.

\subsection{Clinical Experiences}

Each day the healthcare team arrived, there was a fair amount of setup and work to be done before patients could be seen. It was not unusual to find at least a dozen patients waiting when our bus arrived. The team saw approximately 100 patients/day averaging 500 patients per week. The students functioned in a rotating fashion in the roles of triage nursing, physical assessment with the provider, pharmacy staff, day care staff, and a floating student that we referred to as the Clinic Leader.

When assigned to triage, each student, with the help of a translator, performed vital signs, asked pertinent questions related to their health, and quickly self-identified when pregnancy testing was indicated. The students became very proficient at this task under the leadership of a Spanish-speaking faculty member who knew these students very well from a previous course. This understanding was of immeasurable benefit as the comfort and trust level between them had already been established.

The exam room became the zone where each student, under the tutelage of a nurse-practitioner or nurse-midwife, learned how to focus the assessment on the patient's admitting complaint. This required an ability to prioritize and focus on what the patient felt was their problem as well as recognize that which the patient did not see. An example was in the gynecological room with the nurse-midwife where a "simple" vaginitis exam would also become a need for breast exam instruction as well as an occasional referral for a breast mass. One student was so focused on "expecting normal" that an obviously-palpable abdominal mass was missed. However, due to the determination to recheck student exam findings, it was discovered by the midwife, who calmly instructed the student to do a recheck in order to determine how it was missed. As is quite commonly the issue, the student had "expected normal". An invaluable lesson in always keeping one's minds open to possibilities was forever learned in that moment by this student.

The pharmacy was one of the most chaotic areas of the clinic. Two students as well as SIFAT personnel were assigned to that area and it still was not enough. These students needed an understanding of the medications that were prescribed, as well as side effects, the proper method of dosing, and the ability to ensure that the patients understood all they were being told. In Spanish. The responsibility in this area of the clinic was extreme and the students felt the stress of it. They were, obviously, the last station to be finished each day and came away exhausted.

Clinic Leaders managed the flow of the patients through the clinic, making sure providers stayed busy and preventing any bottle necks due to unexpected health care issues requiring more time from the providers. For example, one NP needed more time with a patient as a long-term ganglion cyst was removed. With the right equipment the NP had the foresight to bring with him, and the proper means of anesthesia available, a cyst removal 
and dressing application was possible. The patient, who had been rejected for treatment by numerous physicians in the Quito area since it was non-emergent, was ecstatic. The slow-down of this particular provider's patient flow was readily transferred to other providers by the Clinic Leader so that the clinic as a whole continued to function as efficiently as possible. The Clinic Leader had a very demanding and responsible job as he or she needed to quickly recognize the need to divert patients when this sort of "unexpectedness" happened. Most of the students placed in this role took advantage of practicing leadership, assertiveness, and management skills.

The fifth and final area staffed was the daycare. While no detailed skills were necessary in this area, it was vital that the students understood growth and development of various ages and how much to expect from them with attention spans. This is where the students did the service learning teaching portion of the course, and several adaptations from their original plan had to be made once the concern of limited resources was recognized. One day required great ingenuity due to not having water in the clinic, requiring teaching proper handwashing with no water. The demonstration was done with hand sanitizer instead. The biggest skills the students needed in this area was creativity, endurance, and determination.

\subsection{Student Learning Outcomes}

The stated student learning outcomes (Table 1) were supported by this medical- mission focused study abroad, as described in the following paragraphs. Further, students and faculty agreed that students were able to obtain experiences that addressed expected outcomes in ways that surpassed clinical experiences obtained in the home clinical experiences.

Critical thinking was evidenced by process improvement and flexibility. Students, instructors, and providers were constantly evaluating the operation and making adjustments. For example, one student recognized and identified a better waiting area to promote patient confidentiality in triage while another student implemented a safer method to filling and distributing the prescriptions. One morning the team had planned to do only home visits, but upon arrival at the clinic there were about 50 patients already waiting to be seen. The clinic was set up quickly and the patients were seen before lunch. Flexibility in planning was needed every single day.

Holism was very much evident as students welcomed every opportunity to submerge themselves in the local culture and learn about the connection between faith and healing. Church members and day care workers consented for treatment and provided the medical history for the children since they were not accompanied by parents. Students recognized that photographing and treating children without parental consent was very different from the students' home culture. On one occasion, patients that were waiting for care were subject to evangelizing and a student was concerned when they overheard a church volunteer explain to a patient that if they were a believer, they would be cured. These experiences illustrated the blurred lines between religion, culture, and wellness in a way that could not be accomplished in a classroom.

Effective communication was challenging. The clinics were so noisy and busy it was easy for things, both literally and figuratively, to get lost in translation. One student spoke fluent Spanish and a few spoke a little from advanced college courses and prior mission trips which was helpful. Many of the SIFAT staff were also usually available for translation. Healthcare providers were very approachable, which promoted student-provider communication.

Collaboration was essential in all roles at the clinic. Triage required collaboration with the translators, patients and providers. Collaborative practice between all working the pharmacy was continuous and vital to the safety of the patients. To keep patient intake moving and ensure that appropriate care was given, the Clinic Leader role required constant collaboration with all of the personnel involved in the clinic, including the local church volunteers. This experience is almost impossible to attain in home clinical settings.

The implementation of teaching strategies was evidenced in many ways. Handwashing, oral care, and self-breast exams were all effectively taught in spite of few resources available. This experience led to student gratitude for all of the patient education support tools available in their home country as well as empathy for those struggling to meet basic needs.

Demonstration of personal and professional accountability was necessary every day, both logistically and professionally. By 7:00 a.m., students had to be on the SIFAT bus. Quito law requires that vehicles travel at certain times based on their license plate number. This made an on-time departure imperative as a significant traffic delay may result in incurring a heavy fine for traveling outside the designated time. Professionally, individual accountability as part of a team was critical to care for 100 patients a day. Each wheel in the cog was necessary for maximum efficiency. 


\section{Lessons Learned}

This trip was different from the study abroad trips led by the SON in the past. The medical missions focus, with the inherent emphasis on caring and cultural immersion, was a new experience for this team. Needless to say, many lessons were learned. These lessons fall into the general categories of the logistics, students and faculty.

\subsection{The Logistics: Lessons Learned}

\subsubsection{Start Planning Earlier}

The due diligence trip was taken only five months prior to the trip and earnest recruitment of students was not started until four months before the trip. The medical team was also not completely cemented until about that time as well. The medications ordered did not come in until, literally, the day before it was due, making an on-time delivery very anxiety-producing. It is recommended to start planning a full year before the desired trip date.

\subsubsection{Develop More Student Requirements for Participation}

While the minimum academic standard was beneficial, it was determined that additional standards may have improved the team dynamic. Students must understand the physical and emotional demands of this trip, and be equipped to manage any on-going medical issues they may have. Due to the late start in promoting to the students this first time, and the need for a minimum of twelve to make it feasible, all that was required was that students were in good academic standing and had met the course prerequisites. A bit of discretion in terms of maturity may have been beneficial.

\subsection{Students: Lessons Learned}

\subsubsection{Caring and Creativity}

The degree of caring and creativity the students were capable of was remarkable. They quickly took ownership of their role to help others in any way that they could. Many gave their sunglasses to patients with pterygium (an eye condition that results from the powerful rays of the sun at the equator as tissue begins to cover the eye as a protective measure), and one student gave her shoe orthotics to a patient suffering with knee and hip pain. All remained professional, positive, and thoughtful. The instructors who didn't have previous experience with the students in the clinical setting were thrilled to see the student's knowledge, skills and attitudes already well developed and put into action.

\subsubsection{Remember, Students Are Students}

The students appeared so proficient and professional that it was easy for community leaders and staff to forget they were unlicensed undergraduate students. Faculty had to be vigilant that the students were not put into situations beyond their role as a student. Students were reassured by faculty that it was not only acceptable but necessary to say "no" if they were asked to provide care or perform skills they were not comfortable with.

Most students expressed a deep level of frustration regarding the lack of care that was available to the Ecuadorians, and the very little that they could do for them. Emotions often were deep during post-conference time as they reflected on the "lack of" they witnessed. Faculty helped students work through this as much as they could, in part by reminding students that often nursing consists of improving a patient's life just for today, even if it is unlikely the improvement will be long term.

In contrast, while students were capable, creative and adapting, they struggled in other areas. Some traveled without enough of their prescriptions or any recommended over the counter remedies for diarrhea, upset stomach, constipation, or minor aches and pain. In spite of being reminded to bring their own toilet paper, some students would leave for a day long field trip unprepared for bathrooms. Despite an extensive discussion about rules and boundaries, there were times that they stayed out past curfew or went into areas of town that were designated as off limits.

\subsection{Lessons Learned: Faculty Role}

\subsubsection{Faculty Wear Many Hats}

A study abroad nursing faculty participant has many roles including nurse, instructor, mother, mentor, manager, counselor, and friend. Days became very long as each transitioned from one role to the next while striving to be a role model every minute of every day. Role strain is a termed used to describe what expert nurses sometimes experience when a new position is acquired (Clark, 2015). During the clinical experience, there was definitely a constant shifting between the role of "nurse" and the role of "clinical instructor". The day began with over 50 patients, their families, and the church members waiting for the team. It was a constant flux from the nurse role to meet the needs of the patients and healthcare providers, and then back to clinical faculty role to ensure that the 
needs of the students were being met. Faculty became closer to the students during this time together than they do when in a typical classroom setting and there was some concern that the closer student-faculty relationships might become problematic once we returned. This, however, did not happen and relationships went back to "normal" quickly once back in the regular classroom.

\subsubsection{Struggle with How Much Autonomy to Give Students}

It was difficult to judge how much autonomy to give the adult students during off-clinical hours. There was an enormous awareness of faculty responsibility for students who were making their own decisions that could put them in harm's way. Students studying abroad in a third world country are still students. The majority of the team were twenty-somethings with a passion for life that is reflected in that age group. While capable of showing remarkable professionalism, accountability, creativity and empathy, students also pushed boundaries and needed guidance from the faculty.

Intense preparation of students for future trips is needed and prescreening should be considered to make sure they are equipped to handle their own medications, physical readiness, and downtime. Additionally, faculty would benefit from guidance before leaving about how to support students that are facing emotional challenges and frustrations while abroad.

\section{Summary}

In summary, this study abroad experience was one full of rich learning experiences for all who participated. As the original purpose was to respond to the call for cultural competence in nursing education, and to do so within a caring philosophy, the Study Abroad team found success in achieving both goals. As schools of nursing are being challenged to bring a strong foundation for cultural awareness into their curricula, the significance of developing Study Abroad programs cannot be overestimated. This paper provides a basis upon which to start such a venture.

A final recommendation is to further enrich such an experience by coordinating and traveling with other healthcare disciplines. It is our goal to continue to develop this program and hopefully partner with other college disciplines within our university to expand the services we can provide. In the words of Nelson Mandela, "After climbing a great hill, one only finds there are many more hills to climb" (Mandela, 1995). We will keep climbing.

\section{Acknowledgement}

The authors wish to acknowledge Julie S. Williard, RN, NP-C, Thomas G. (Greg) Heath, MSN, RN, FNP-BC, and Jim Martin, Lt. Col., MMOS, MSN, FNP-C for their tireless efforts in support of our students and patients. They made this wonderful experience truly remarkable.

\section{References}

American Association of Colleges of Nursing. (2008) http://www.aacn.nche.edu/education-resources/toolkit.pdf

Audette, J. G., \& Roush, S. E. (2013). Educational perspectives and teaching styles of faculty who lead international service learning experiences. Journal of Physical Therapy Education, 27(2), 65-77.

Bentley, R., \& Ellison, K. (2007). Increasing cultural competence in nursing through international service$\begin{array}{llll}\text { learning } & \text { Nurse } & \text { Educator, } & 32(5),\end{array}$ https://doi.org/10.1097/01.NNE.0000289385.14007.b4

Betancourt, J., Corbert, J., \& Bondaryk, M. (2014). Addressing disparities and achieving equity: Cultural competence, ethics, and health care transformation. Chest, 145(1), 143-148. https://doi.org/10.1378/chest.13-0634

California Endowment. (2003). Principles and recommended standards for cultural competence education of health care professionals. Woodland, CA: Author.

Clark, C. L. (2013). A Mixed-Method Study on the Socialization Process in Clinical Nursing Faculty. Nursing Education Perspectives, 34(2), 106-110. https://doi.org/10.5480/1536-5026-34.2.106

Duffy, J. (2009). Quality caring in nursing: Applying theory to clinical practice, education and leadership. New York, NY: Springer.

Hegedus, K. S, McNulty, J., Griffiths, L., Engler, A., Cabrera, L., \& Rose, V. (2013). Developing and Sustaining a Study Abroad Program as Viewed Through a Caring Lens. International Journal for Human Caring, $17(1), 29$. 
Hills, M., \& Watson, J. (2011). Creating a caring science curriculum: An emancipatory pedagogy for nursing. New York, NY: Springer.

Institute of Medicine. (2002, March). Unequal treatment: Confronting racial and ethnic disparities in health care. Retrieved from https://iom.nationalacademies.org/Reports/2002/Unequal-Treatment-Confronting-Racial-and-Ethnic-Dispar ities-in-Health-Care.aspx

Kohlbry, P. W. (2016). The impact of international service-learning on nursing students' cultural competency. Journal of Nursing Scholarship, 48(3), 303-311. https://doi.org/10.1111/jnu.12209

Larsen, R., \& Reif, L. (2011). Effectiveness of cultural immersion and cultural classes to increase cultural awareness. Journal of Nursing Education, 50(6), 350-354. https://doi.org/10.3928/01484834-20110214-04

Leiniger Leininger, M., \& McFarland, M. (2006). Culture care diversity and universality: A worldwide theory. CT: Jones and Bartlett.

Long, T. (2012). Overview of teaching strategies for cultural competence in nursing students. Journal of Cultural Diversity, 19(3), 102-108.

Mandela, N. (1995). The Long Walk to Freedom. Little, Brown, and Company.

Memmot, R. J., Coverston, C. R., Heise, B. A., Williams, M., Maughan, E. D., Kohl, J., Palmer, S. (2010). Practical Considerations in Establishing Sustainable International Nursing Experiences. Nursing Education Perspectives, 31(5), 301.

Payne-Jackson, A., Haynes, A., \& Scott, K. (2014). Howard University Service-Learning Projects. Currents in Teaching \& Learning, 7(1), 89-99.

Wilson, C. B., \& Grams, K. (2013). The lived experience of BSN students in caring groups: Priceless. International Journal for Human Caring, 17(3), 13-19.

\section{Copyrights}

Copyright for this article is retained by the author(s), with first publication rights granted to the journal.

This is an open-access article distributed under the terms and conditions of the Creative Commons Attribution license (http://creativecommons.org/licenses/by/4.0/). 